\title{
A RARE PRESENTATION OF CALVARIAL METASTASIS FROM FOLLICULAR CARCINOMA THYROID -A CASE REPORT
}

MuraliswarRao J ${ }^{1}$, Surabi Karthik ${ }^{2}$, Aswini T ${ }^{3}$, Rakesh Kumar Nanna ${ }^{4}$, Naga Karthik $\mathrm{G}^{5}$

\section{HOW TO CITE THIS ARTICLE:}

MuraliswarRao J, SurabiKarthik, Aswini T, Rakesh Kumar Nanna, Naga Karthik G. "A Rare Presentation Of Calvarial Metastasis From Follicular Carcinoma Thyroid -A Case Report". Journal of Evolution of Medical and Dental Sciences 2013; Vol2, Issue 50, December 16; Page: 9679-9684.

ABSTRACT:Bone metastases are common but serious complication of aggressive thyroid carcinoma, but calvarial metastasis is relatively uncommon complication of the primary tumor of thyroid gland. We are presenting an unusual case report of large calvarial metastasis which had both intracranial and extra cranial components of a previously diagnosed and operated case of follicular carcinoma of thyroid.

KEY WORDS: Calvarial metastasis, primary follicular carcinoma of thyroid, skeletal metastasis in thyroid carcinoma.

INTRODUCTION:Metastases to the skeletal system from thyroid carcinoma are a well-known event, constituting the second most common systemic site of involvement after lungs. The poor prognosis associated with bone metastases of differentiated thyroid cancer might partly be due to the fact that they are rarely detected at an early stage. Carcinoma of the thyroid gland is one of the possibly curable cancers. At the time of initial diagnosis, $1 \%-3 \%$ of patients with thyroid cancer may have distant metastases, whereas another 7\%-23\% will develop distant metastases during the disease course ${ }^{2,12}$ 16.The distant metastases, especially those involving bone, increase mortality rate, compromise quality of life and shorten patient survival.

After lung, bone is the most common site of systemic metastasis from thyroid carcinoma 1,2 , the overall reported incidence ranging from $1 \%{ }^{3}$ to more than $40 \%{ }^{4}$. This incidence varies according to the primary tumour type, with follicular carcinoma showing a much higher frequency than the papillary or anaplastic subtypes in most reported series ${ }^{1,2,5-8}$.Approximately $90 \%$ of non-medullary thyroid malignancies are well differentiated and are classified as papillary or follicular. Patients with differentiated thyroid carcinoma (DTC) have a high 10-year survival rate (80\%-95\%), except in the presence of metastatic disease (40\% 10-year survival). Incidence of bone metastases is Vertebrae (54\%), Pelvis (50\%), Ribs (31\%), Femur (21\%), Skull (13\%) and Humérus (11\%).

Among the different histologic subtypes, follicular carcinoma is most likely to show bone metastases, with reported incidences ranging from $7 \%$ to approximately $28 \%$. The poor prognosis associated with bone metastases of differentiated thyroid cancer might partly be due to the fact that they are rarely detected at an early stage. The influence of the microscopic tumor type and tumor differentiation on survival after bone metastasis primarily appears to be due to the much worse prognosis among anaplastic and medullary carcinomas. Age at diagnosis of bone metastases does not influence survivals.

CASE REPORT:A 44 year old woman with past history of total thyroidectomy for follicular thyroid carcinoma, proved postoperatively, presented with large gradually increasing swelling in the occipital region since 6 to 7 years with no significant associated pain. 
The patient was subjected to radiograph of skull AP \& lateral views, CT Brain, CT angiography and MRI Brain. Radiograph skull showing large osteolytic lesion causing near total destruction of the bone and associated with large disproportionate soft tissue component. CT brain plain and contrast showed evidence of large heterogenouspredominantly soft tissue density lesion with destruction of the underlying occipital bone and a large extradural component causing compression of occipital and parietal lobes. The lesion is showing heterogenous enhancement on contrast administration with multiple focal non-enhancing hypodense areas, suggestive of cystic / necrotic areas. MRI brain showed large lobulated heterointense lesion predominantly iso to hyper intense on FLAIR, T1WI \& T2WI in the occipital region. The lesion is causing destruction of underlying bone \& extending intracranially into the extradural space, causing mass effect in the form of compression of bilateral occipital, parietal lobes with no significant adjacent cerebral edema. On contrast administration the lesion showed heterogeneous enhancement. CT angiogram showed the lesion is intensely vascular. The diagnosis is of a highly vascular predominantly soft tissue density lesion causing destruction of the underlying occipital bone and a large extra dural component. In view of a known primary in the thyroid with post total thyroidectomy possibility of a metastatic lesion was considered. Surgery was done and the specimen sent for histopathology, it revealed evidence of follicular pattern cells with nuclear cluster with features of tumor emboli suggestive of follicular carcinoma thyroid deposit.

DISCUSSION:Metastases to the skeletal system from thyroid carcinoma are a well-known event, constituting the second most common systemic site of involvement after lungs 1,2, 9 . The overall reported incidence of bone metastasis from thyroid carcinoma has ranged from less than $1 \%$ to more than $40 \%$ 2-4,8,9-11. Among the different histologic subtypes, follicular carcinoma is most likely to show bone metastases, with reported incidences ranging from $7 \%$ to approximately $28 \% 8,9,12$. Most studies of thyroid carcinomas that result in bone metastases show a preponderance of follicular over papillary carcinoma (46\%-93\% versus 7\%-40\%) or other types of thyroid cancers $8,11,13,14$. However, the relatively recent studies by Wood et al ${ }^{15}$, Ruegemer et al ${ }^{16}$, and Mizukami et al ${ }^{17}$ report a much higher relative incidence of papillary carcinoma among their cases with bone metastases (41\%-77\%).

Calvarial metastases are usually asymptomatic and discovered incidentally on radiographic studies. The imaging techniques to detect bone metastatic lesions include plain radiography, computed tomography (CT), magnetic resonance imaging (MRI), isotope bone scans, positron emission tomography (PET), radioiodine uptake, and others. The management of primary thyroid cancer is multidisciplinary, including surgeons, endocrinologists, nuclear medicine physicians, and radiotherapists. The 5-year survival rates for patients with bone metastases ranged from $53 \%$ to $84 \%$ in previous reports $2,18,19$.The most common presenting symptom is a visible, localized swelling of the skull produced by a growing tumor that erodes the outer table. Tumors can also expand through inner skull tables and apply direct pressure on adjacent brain parenchyma. Rarely, they may be associated with either subdural or epidural hematomas. Focal sensorimotor deficits and seizures occasionally result from progressive inward growth of a calvarial metastatic lesion or associated subdural hematoma. 
CONCLUSION:The presence of distant metastases is considered one of the most important indicators of unfavorable prognosis in differentiated thyroid carcinomas. The poor prognosis associated with bone metastases of differentiated thyroid cancer might partly be due to the fact that they are rarely detected at an early stage. In conclusion, thyroid carcinoma can present with bone metastases in its early stage. Early detection and management should help disease control and improve patient's quality of life. A high index of suspicion is needed to detect these early bone metastases at the initial visit, allowing prompt and thorough follow-up during clinical practice.

\section{IMAGES:}

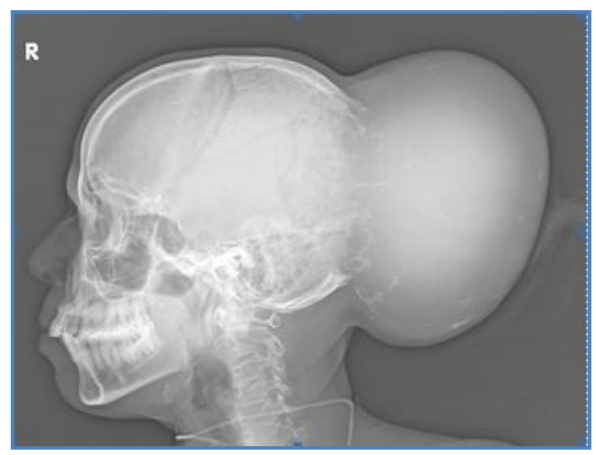

Image 1: Plain radiograph of skull lateral view showing a large well-defined homogenous opacity noted in the posterior aspect of skull with near total destruction of the underlying occipito-parietal bones.
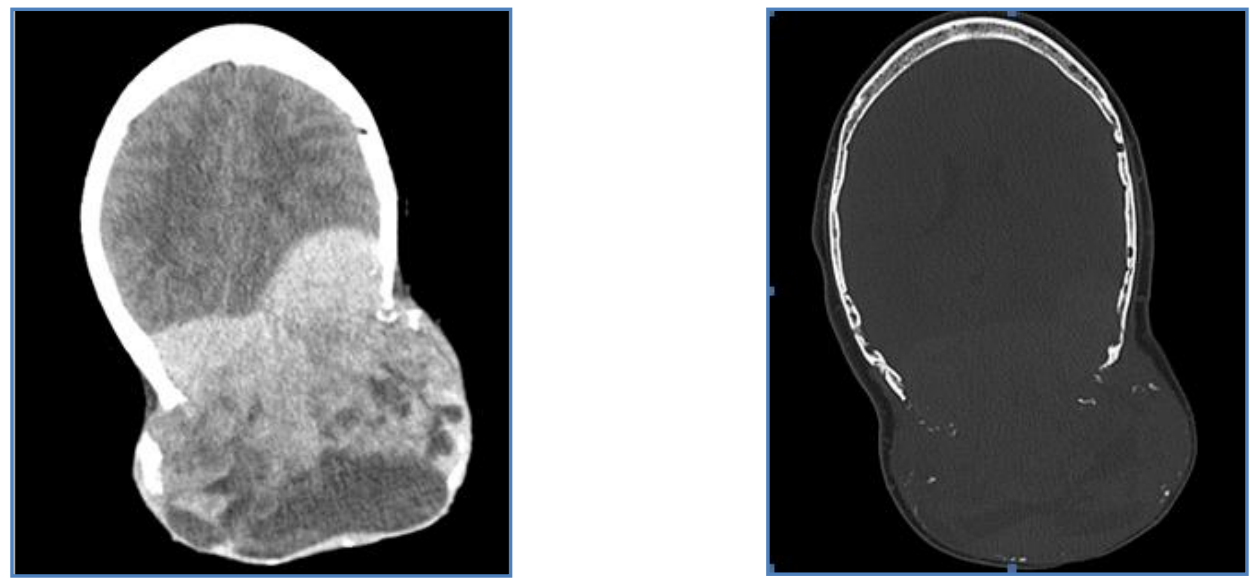

Image 2 and 3: CT brain plain axial sections parenchymal and bone window show relatively well defined heterogenous predominantly hyperdense soft tissue density lesion with multiple ill-defined cystic spaces noted in the posterior aspect of the occipito-parietal region with destruction of the underlying bone and with intracranial extension. 


\section{CASE REPORT}

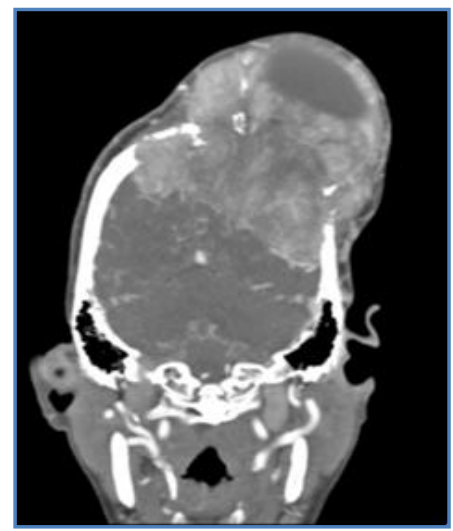

Image 4: CT brain post contrast coronal image shows intense heterogenous enhancement of the lesion with compression of the occipito-parietal lobes.

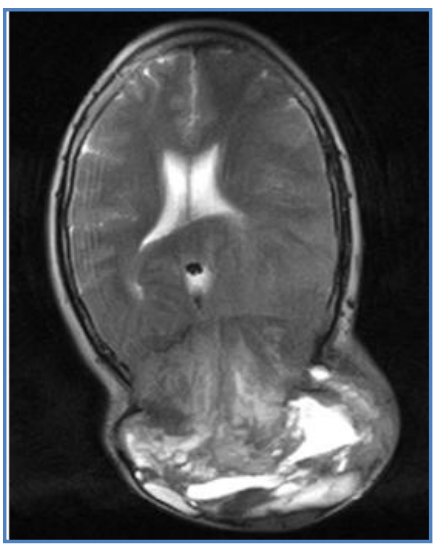

Image 5: MRI brain T2WI axial image shows the lesion is of a large heterointense, predominantly hyperintense to the surrounding cortex noted in posterior aspect of the occipito-parietal region with intracranial extension with ill-defined hyperintense cystic spaces.

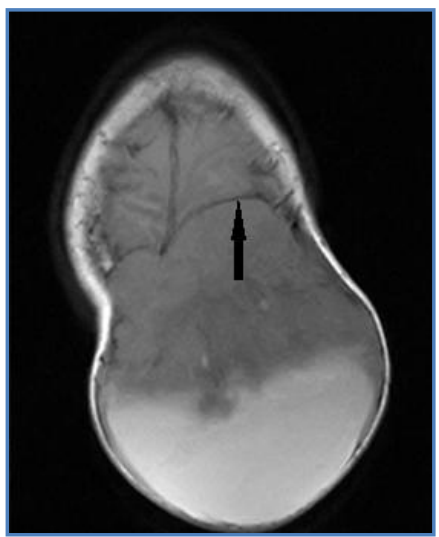

Image 6: MRI brain T1WI axial image shows the lesion is isointense to the adjacent cortex compressing the occipito-parietal lobes and limited by dura( $\uparrow)$. 


\section{CASE REPORT}

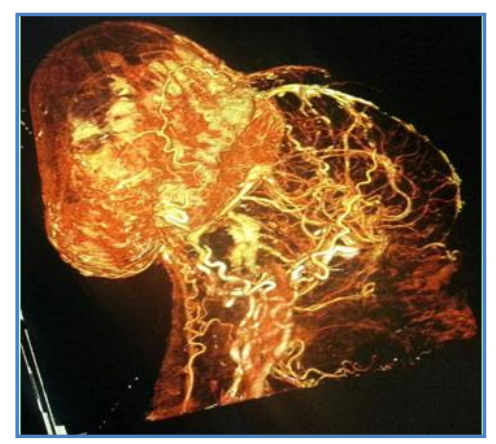

Image 7: CT cerebral angiography 3D VRT reconstructed image shows a highly vascular lesion with prominent vascular channels noted within the lesion and the major vascular supply from external carotid artery.

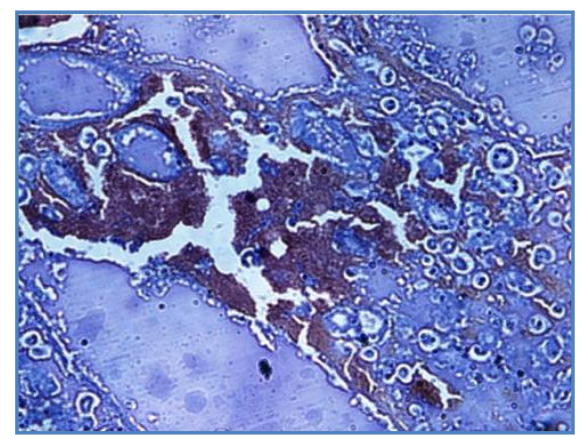

Image 8:Histopathological slide shows revealed evidence of follicular pattern cells with nuclear cluster with features of tumor emboli suggestive of follicular carcinoma thyroid deposit.

\section{REFERENCES:}

1. Proye CAG, Dromer DHR, Carnaille BM, et al. Is it still worthwhile to treat bone metastases from differentiated thyroid carcinoma with radioactive iodine? World J Surg. 1992; 16:640646.

2. Schlumberger $M$, Tubiana $M$, de Vathaire $F$, et al. Long-term results of treatment of 283 patients with lung and bone metastases from differentiated thyroid carcinoma. J ClinEndocrinolMetab. 1986;63:960-967.

3. Simpson WM. Clinical and pathological study of 55 malignant neoplasms of thyroid gland. Ann Clin Med. 1926; 4:643-667.

4. Hubeny MJ, Mass M. Roentgenologic aspects of metastases. Radiology. 1940; 35:315-321.

5. Carcangiu ML, Zampi G, Pupi A, Castagnoli A, Rosai J. Papillary carcinoma of the thyroid: a clinicopathologic study of 241 cases treated at the University of Florence, Italy. Cancer. 1985; 55:805-828.

6. Heitz P, Moser H, Staub JJ. Thyroid cancer: a study of 573 thyroid tumors and 161 autopsy cases observed over a thirty-year period. Cancer. 1976; 37: 2329-2337.

7. Massin J-P, Savoie J-C, Garnier H, Guiraudon G, Leger FA, Bacourt F. Pulmonary metastases in differentiated thyroid carcinoma: study of 58 cases with implications for the primary tumor treatment. Cancer. 1984; 53:982-992.

8. McCormack KR. Bone metastases from thyroid carcinoma. Cancer. 1966; 19:181-184. 
9. Hay ID, Rock MG, Sim FH, Swee RG, Unni KK, Gunderson LL. Metastatic bone cancer: thyroid cancer. In: Sim FH, ed. Diagnosis and Management of Metastatic Bone Disease: A Multidisciplinary Approach. New York, NY: Raven Press; 1988:305-317.

10. Mizukami Y, Mishigishi T, Nonomura A, et al. Distant metastases in differentiated thyroid carcinomas: a clinical and pathologic study. Hum Pathol. 1990; 21:283-290.

11. Tsuchiya A, Watanabe I, Hoshi T, et al. Bone metastasis of thyroid carcinoma. Gan No Rinsho. 1978;24:1187-1190.

12. Harness JK, Thompson NW, McLeod MK, Eckhauser FE, Lloyd RV. Follicular carcinoma of the thyroid gland: trends and treatment. Surgery. 1984;96:972- 980.

13. Niederle B, Roka R, Schemper M, Fritsch A, Weissel M, Ramach W. Surgical treatment of distant metastases in differentiated thyroid cancer: indication and results. Surgery. 1986;100:10881097.

14. Nagamine Y, Suzuki J, Katakura R, Yoshimoto T, Matoba N, Takaya K. Skull metastasis of thyroid carcinoma: study of 12 cases. J Neurosurg. 1985; 63:526-531.

15. Wood WJ Jr, Singletary SE, Hickey RC. Current results of treatment for distant metastatic welldifferentiated thyroid carcinoma. Arch Surg. 1989;124: 1374-1377.

16. Ruegemer JJ, Hay ID, Bergstralh EJ, Ryan JJ, Offord KP, Gorman CA. Distant metastases in differentiated thyroid carcinoma: a multivariate analysis of prognostic variables. J ClinEndocrinolMetab. 1988;67:501-508.

17. Mizukami Y, Mishigishi T, Nonomura A, et al. Distant metastases in differentiated thyroid carcinomas: a clinical and pathologic study. Hum Pathol. 1990; 21:283-290.

18. Chen MH, Chang CC, Huang TS, et al. Factors affecting long-term survival of Taiwanese patients with medullary thyroid carcinoma. J. Formos. Med. Assoc. 2003;102:73.

19. Fanchiang JK, Lin JD, Huang MJ, et al. Papillary and follicular thyroid carcinomas with bone metastases: a series of 39 cases during a period of 18 years. Changgeng Yi XueZaZhi. 1998; 21:37.

\section{AUTHORS:}

1. MuraliswarRao J.

2. SurabiKarthik

3. Aswini T.

4. Rakesh Kumar Nanna

5. Naga Karthik G.

\section{PARTICULARS OF CONTRIBUTORS:}

1. Associate Professor, Department of Radiodiagnosis, Asram Medical College.

2. Post Graduate, Department of Radiodiagnosis, Asram Medical College.

3. Senior Resident, Department of Radiodiagnosis, Asram Medical College.

4. Post Graduate, Department of Radiodiagnosis, Asram Medical College.
5. Post Graduate, Department of Radiodiagnosis, Asram Medical College.

\section{NAME ADRRESS EMAIL ID OF THE CORRESPONDING AUTHOR:}

Dr. MuraliswarRao J,

Associate Professor,

Department of Radiodiagnosis,

Asram Medical College, Eluru,

West Godavari (DT), Andhra Pradesh, India.

Email-muraliradiology@gmail.com

Date of Submission: 16/11/2013.

Date of Peer Review: 18/11/2013.

Date of Acceptance: 28/11/2013.

Date of Publishing: 10/12/2013 